\title{
EL NOTARIAT A REUS AL SEGLE XIII: \\ UNA APORTACIÓ A LA SEVA HISTÒRIA ${ }^{1}$
}

\author{
DANIEl PIÑOL ALABART \\ Universitat de Tarragona
}

\section{SUMARI}

1. Introducció.- 1.1. Per a un estat de la qüestió- 2. El notariat i el seu funcionament a Reus.- 2.1. Els notaris $i$ els escrivans.- 3 . Els manuals notarials.- 3.1. Característiques dels llibres.

\section{INTRODUCCIÓ}

Amb aquest treball no pretenem res més que aproximar-nos, en una primera presa de contacte, a la implantació de la institució notarial a Reus al llarg del segle XIII i presentar els principals trets del seu funcionament ${ }^{2}$. De fet és aquest un segle clau per al notariat ja que és el moment en que arriben poc a poc els usos i costums dels notaris bolonyesos i el Dret Comú es difón cada vegada més profundament arribant-se a produir una veritable

'La publicació d'aquest estudi s'inscriu dins de les activitats del projecte de recerca PS950161, dirigit per la Dra. Coral Cuadrada i del qual en formem part. Tanmateix agraïm a les professores M. Sanmartí i C. Cuadrada la revisió de l'original i els suggeriments que ens han fet per tal de millorar-lo.

${ }^{2}$ Aquest article no és més que una part molt petita del que serà la nostra tesi doctoral, dirigida per la Dra. Montserrat Sanmartí i que es centra en l'estudi dels notaris al Camp de Tarragona al llarg del segle XIII i fins l'any 1351. El treball ha estat possible gràcies a una beca de recerca que ens fou concedida per la Universitat Rovira i Virgili l'any 1995 per a la realització d'una tesi doctoral.

"Anuario de Estudios Medievales", 26 (1996) 
renovació documental ${ }^{3}$. És aquest també el moment en que es dóna el pas de l'escrivent al notari públic, de la charta a l'instrumentum, tot per la influència del renaixement del Dret iniciat a Bolonya ja al segle $\mathrm{XI}^{4}$. Canvi, renovació, més aviat transformació en el món notarial, una institució que va agafant cos i es va obrint pas en una societat que necessita dels seus serveis per a validar els seus actes, molt lligats a les transaccions comercials, al mercat, al tràfic marítim, als canvis econòmics que s'estan donant en el conjunt de la societat ${ }^{5}$. És en aquest context que emmarquem el present article tot centrant-lo en el funcionament i l'organització del notariat a Reus en la tretzena centúria.

La documentació que utilitzem és la notarial. Així hem buidat els pergamins guardats a l'Arxiu Històric Comarcal de Reus (AHCR) anteriors al segle XIV i que ens mostren les subscripcions notarials i la forma de validació des de mitjans del segle XII fins arribar a l'any 1300. També hem revisat els manuals notarials. A Reus se'n guarden des de l'any 1292, alguns en un estat de conservació bastant dolent, protocols que hem treballat exhaustivament i dels quals n'extreiem dades bàsiques per al nostre treball. Ho fem seguint autors que han suggerit temes de recerca entorn d'aquesta institució i que proposen l'anàlisi dels protocols i dels documents en pergamí per a estudiar el funcionament i l'activitat dels notaris ${ }^{6}$. 33.

${ }^{3}$ José Bono Huerta, Historia del Derecho Notarial Español, I, 2, Madrid, 1982, pp. 31-

${ }^{4} \mathrm{C}$ fr. Josep M. Pons Guri, De l'escrivent al notari i de la 'charta' a l'instrument. Recepció dels usos notarials itàlics a Catalunya, "Lligall", 7(1993), pp. 29-32. Rafael CONDE I Delgado DE Molina, El pas de l'escrivà al notari, "Actes del I Congrés d'Història del Notariat Català", Barcelona, 1994, pp. 439-462. José BONO HUERTA, Idem, I, 1, Madrid, 1979, pp. $165-170$.

${ }^{5}$ Francisco Gimeno Blay, La escritura gótica en el País Valenciano después de la conquista del siglo XIII, València, 1985, pp. 64-66.

${ }^{6} \mathrm{Cfr}$. Rosa M. BLASCo MARTínez, Una aproximación a la institución notarial en Cantabria, Santander, 1990, pp. 51-52. José BONO HUERTA, Los archivos notariales, Sevilla, 1985, pp. 48-58. Altres pautes les trobem en Honorio GARCía GARCía, Reflexiones sobre la manera de investigar la Historia del Notariado, "La Notaría", 82(1947), pp. 381-390. També hi ha una proposta de recerca a partir de documentació notarial i de les subscripcions dels escrivans en Aquilino IGLESIA FERREIRós, La difusión del Derecho Común en Cataluña, "El Dret Comú i Catalunya. Actes del I Simposium Internacional 1990", Barcelona, 1991, pp. 143156. José A. MARTín FUERTES, Los notarios en León durante el siglo XIII, "Notariado público y documento privado", València, 1989, pp. 597-613 utilitza igualment les subscripcions per a veure l'evolució i la implantació del notariat públic, si bé en un àmbit molt diferent. 


\subsection{Per a un estat de la qüéstió}

Ja fa uns anys que es marcaren algunes pautes per a l'estudi de la institució notarial i de les notaries ${ }^{7}$. No fou res més que el tret de sortida d'una cursa a la que encara li queda un bon camí per córrer, malgrat els nombrosos fruits que ha donat. Tot i que no volem oblidar els estudis clàssics $^{8}$ sobre el tema veiem clar com, un dels primers de fer-se ressò d'aquelles propostes fou Josep Trenchs ${ }^{9}$. Amb un recull bibliogràfic sobre el notariat posava de manifest la riquesa en treballs sorgits de la historiografia notarial però també la gran quantitat de qüestions que encara no havien estat abordades. Trenchs, paral-lelament a altres investigacions, iniciava una sèrie de treballs sobre les cancelleries ${ }^{10}$ seguint en part el discurs de Canellas. Malgrat les llacunes i la manca d'estudis de conjunt sobre els notaris han anat apareixent resultats destacats a partir de les investigacions dutes a terme per autors com M.Teresa Ferrer Mallol o Josep M. Pons Guri $^{11}$, demostrant en gran manera l'interès que hi ha a Catalunya pels

\footnotetext{
${ }^{7}$ Angel CANELlaS LÓPEZ, La investigación diplomática sobre cancillerías y oficinas notariales: estado actual "Actas de las Primeras Jornadas de Metodología aplicada a las Ciencias Históricas", vol. V, Santiago de Compostela, 1975, pp. 201-222. En la tercera part de la seva exposició es presenten les possibilitats de la recerca, com ara són l'elaboració d'un bibliografia, l'edició d'una specimina de documents originals, fixar un vocabulari tècnic, reunir les ordinacions jurídiques sobre el notariat i proposar unes normes de publicació de documents. També es planteja la realització de nòmines d'escrivans i notaris i els estudis monogràfics sobre les notaries, a part de la utilització dels protocols notarials per a estudiar tipologies documentals o per a reconstruir la religiositat a partir dels testaments.

${ }^{8}$ Francesc CARRERAS CANDI, Desenrrotllament de la institució notarial a Catalunya en lo segle XIII, Barcelona, 1906. Victorino SANTAMARÍa, Contribución a la historia del Notariado en Cataluña, Barcelona, 1917. Félix DuRÁn Cañameras, Notas para la historia del Notarido catalán "Estudios Históricos y Documentos de los Archivos de Protocolos" (d'aquí en endavant EHDAP), 3 (1955), pp. 71-207.

9Josep TRENCHS ODENA, Bibliografía del notariado en España (sigloXX), "EHDAP", IV (1974), pp. 193-237. Treball publicat abans que les Actes del Congrés d'on va sortir la primera idea del recull bibliogràfic.

${ }^{10}$ Entre altres treballs sobre aquest tema destaquem els següents: La Cancillería de Enrique IV, rey de Cataluña (1462-1464): Unas notas, "Anales de la Universidad de Alicante. Historia Medieval", 1(1982), pp. 195-206; Las cancillerías de la Corona de Aragón y Mallorca desde Jaime I a la muerte de Juan II, Saragossa, 1983; Casa, corte y cancillería de Pedro el Grande. 1276-1285, Roma, 1991.

"Maria Teresa FERRER I MALlol, La redacció de l'instrument notarial a Catalunya. Cèdules, manuas, llibres $i$ cartes, "EHDAP", IV(1974), pp. 29-211; Notariat laic contra notariat eclesiàstic. Un episodi de la pugna entre ambdóss a Girona (1374-1378), "EHDAP", V (1977), pp. 19-34; Cartes $i$ bitllets privats en els manuals del notari barceloní Narcís Guerau Gili (segle XV), "Miscel.lània Aramon i Serra", vol. II, Barcelona, 1980, pp. 197-217. Josep M. PONS GURI, Característiques paleogràfiques dels llibres notarials catalans fins al 1351,
} 
notaris i la seva història. Aquest fet quedà consolidat en la celebració del Primer Congrés d'Història del Notariat Català l'any 1994.

Aquest suposà doncs una plataforma per al debat i el discurs entorn del notariat però també creiem que fou una empenta per a la historiografia sobre el tema, com ho és igualment la publicació dels catàlegs dels fons notarials dels arxius i l'edició de protocols notarials medievals ${ }^{12}$.

Seguint aquesta línia d'augment de la producció de literatura notarial han anat apareixent estudis que aporten noves dades i que van omplint poc a poc els buits que encara hi han en la recerca sobre el notariat ${ }^{13}$.

A nivell local el notariat com a institució, la seva organització, el funcionament de les notaries... és encara un dels desconeguts per a la historiografia. A part de l'inventari del ric fons notarial de l'Arxiu Històric Arxidiocesà de Tarragona tan sols hi ha un treball important centrat en l'edició de l'anomenat Manual d'Alcover, volum conservat precisament en aquest arxiu' ${ }^{14}$. Des del Departament d'Història Medieval, Paleografia i Diplomàtica de la Universitat de Barcelona es va procedir a analitzar el considerat fins fa poc el protocol notarial més antic conservat ${ }^{15}$. El treball

publicat a "Recull d'Estudis Jurídics Catalans", vol.1, Barcelona, 1989, pp. 191-218; Algunes orientacions per a la utilització dels fons de seccions històriques en districtes notarials, Idem, 1989, pp. 159-190; Llibres notarials catalans, "Rubrica. Trivium, Quadrivium, Studium. Las abreviaturas en la enseñanza medieval" 4 (1990), pp. 97-109.

${ }^{12}$ De catàlegs de protocols notarials que facin referència a la zona en la que centrem el nostre estudi hi ha publicat, el de Valls a càrrec de Joan PAPELL, Catàleg dels protocols notarials de Valls. Un altre catàleg que també és del nostre interès és l'elaborat per Salvador RAMON I VINYES; Manuel M. FUENTES I GASÓ, Inventari dels protocols notarials de l'Arxiu Històric Arxidiocesà de Tarragona, Dep. de Cultura de la Generalitat de Catalunya, Barcelona, 1987. De l'edició de procolos notarials comptem fins ara amb Laureà PAGAROLAS I SABATÉ, El protocol del notari Bonanat Rimentol (1351), Barcelona, 1991. Pere PUIG I USTRELL, Capbreu primer de Bertran acòlit, notari de Terrassa, 1237-1242, 2 vols., Barcelona, 1992. Gener Gonzalvo; M.Carme Coll; Oliva SAMPron, El protocol del notari Pere de Folgueres (1338), Barcelona, 1996

${ }^{13}$ Maria Teresa FERRER I MALLOL, L'expansió d'una regalia al començament del segle XIV: el notariat reial, "EHDAP", 13 (1995), pp. 55-73. Rafael GINEBRA I MOLINS, ACF-1 (12301233). El primer volum de l'Arxiu de la Cúria Fumada de Vic, "EHDAP", 13 (1995), pp. 1145. Laureà PAGAROLAS I SABATÉ, Notaris i auxiliars de la funció notarials a les escrivanies de la Barcelona medieval, "Lligall", 8 (1994), pp. 53-72.

${ }^{14}$ Publicat a "Rubrica. De scriptis notariorum", III (1989), pp. 161-294. Sobre aquest manual es va publicar també un breu resum a càrrec dels mateixos professors, Un registro notarial de Alcover del siglo XIII, "Notariado público y documento privado", València, 1989, pp. 507-511.

${ }^{15}$ Cfr. Josep M. PONS GuRı, op.cit., (1993), pp. 32-33. S'han localitzat uns folis a l'Arxiu de la Seu de Manresa que pertanyen a un protocol notarial i que semblen anteriors al d'Alcover, datat a l'any 1228-1229. Concretament aquells estan compresos entre els anys 1222 i 1225. 
va donar com a resultat la transcripció, acompanyada de les regestes de cada nota i d'un estudi introductori. Els notaris han estat tractats també en altres treballs, alguns ja fora de l'època medieval, aportant dades que s'escapen de l'abast de la nostra recerca. Un breu estudi sobre els notaris a Valls al segle XIV, un altre sobre la concessió del privilegi reial a Tarragona per tal de crear un col-legi notarial i un tercer que s'emmarca dins del segle XVIII i presenta la nòmina dels notaris tarragonins tot relacionant-ho amb altres dades però sense arribar a cap fita concloent ${ }^{16}$. Al costat d'aquests treballs destaquem algun estudi sobre els formularis notarials, eines importants i fonamentals per a l'activitat de les escrivanies i dels quals es donen algunes referències ${ }^{17}$.

Tot i que no volem ser exhaustius no podem deixar fora del comentari aquells treballs que han utilitzat els protocols notarials com a base documental ${ }^{18}$. I és que ja fa temps que les fonts notarials són considerades com a fonamentals per a estudis sobre economia, societat i l'anomenada Història de les mentalitats ${ }^{19}$.

Aquest és el panorama historiogràfic entorn de la institució notarial i la seva activitat. La profusió d'estudis no és desbordant encara tot i que ja es comencen a veure algunes llums amb el que s'ha anat fent. Treballs que

\footnotetext{
${ }^{16}$ Joan PAPELL, Aportació documental a la història del notariat a Valls. L'acta de conciliació entre el rector, titular de la notaria, i els síndis de la vila (1319), "Estudis sobre història de la institució notarial", Barcelona, 1988, pp. 107-114. Elisabeth BALDOR ABRIL; Marta INGLÉs Agudo, La situació del notariat català a la ciutat de Tarragona, a les darreries del segle XVI, "Pedralbes. Revista d'Història Moderna", 13, II (1993), pp. 313-317. Aquest va ser presentat en el Tercer Congrés d'Història Moderna de Catalunya l'any 1993 però no trascendeix més enllà de la simple exposició i comentari de les notícies que ofereix la pròpia font. Manel GÜELL, Notes sobre el col-lectiu notarial tarragoni del segle XVIII, "Actes del I Congrés d'Història del Notariat Català", Barcelona, 1994, pp. 667-683.

${ }^{17} \mathrm{Com}$ a exemple vegi's Ferran VALLS TABERNER, Un formulari juridic del segle XII, "Anuario de Historia del Derecho Español" (Madrid), III (1926), pp.508-517, article que es centra en l'estudi d'un formulari procedent del monestir de Santes Creus i inserit al ms. 71 de la Biblioteca Pública de Tarragona.

${ }^{18} \mathrm{Per}$ a l'entorn més immediat objecte del nostre estudi i com a treball que ens és de gran utilitat per a conèixer la societat dels segles XIII-XIV Cfr. Maria BONET DONATO, Aproximació a la societat i economia de Tarragona a la Plena Edat Mitjana, Diputació de Tarragona, 1996. Utilitza de forma gairebé exclusiva els manuals notarials de Tarragona anteriors al 1348. També en la nostra tesi de llicenciatura hem analitzat els testaments per a fer un estudi sobre la religiositat baixmedieval i les actituds davant la mort al Reus del segle XIV. La tesina va ser dirigida per la Dra. Coral Cuadrada i fou defensada l'any 1995. Premiada ex aequo al XIV Premi d'Investigació Històrica de Reus: Antoni Pedrol Rius, ara es troba en curs de publicació amb el títol $A$ les portes de la mort. Religiositat $i$ ritual funerari al Reus del segle XIV.

${ }^{19} \mathrm{Cfr}$. "Actas del II Coloquio de Metodología Histórica Aplicada: la documentación notarial y la historia", 2 vols., Santiago de Compostela, 1984.
} 
aprofundeixen en aspectes concrets del notariat ens són fonamentals per a conèixer el funcionament d'una institució tan arrelada al nostre país. No obstant, per al Camp de Tarragona, és evident que es tracta d'un tema completament inexplorat malgrat els pocs intents d'aproximació.

\section{El NOTARIAT I EL SEU FUNCIONAMENT A REUS}

Parlar del segle XIII a Reus vol dir, en part, no deixar de banda els problemes generats entorn de la senyoria de l'arquebisbe al Camp. I és que el prelat metropolità, conjuntament amb tot l'estament eclesiàstic, té una presència importat a Tarragona i al seu territori ja que el 1118 el comte de Barcelona va fer donació de la ciutat i del Camp a l'arquebisbe Oleguer ${ }^{20}$. El comte i l'arquebisbe compartiren des de l'any $1173^{21}$ la senyoria i a partir d'aquesta situació es derivaren problemes jurisdiccionals i de lluita pel poder que han estat ampliament tractats per la historiografia.

Reus no es va veure marginada en tots aquests afers. El 1154 el senyoriu reusenc fou repartit pel prelat Bernat Tort entre Bertran de Castellet i el Capítol. A cada un d'ells els pertocaren 2 i 1 terç respectivament ${ }^{22}$. L'arquebisbe es reservava per a ell l'església que s'hi havia de construir. L'organització del territori estava marcada amb unes pautes mínimes, arribant-se a perfeccionar amb la concessió de les cartes de població a la vila els anys 1183 i 1186 . Aquestes foren atorgades per Bertran de Castellet la primera i per Joan de Sant Boi, cambrer de la seu de Tarragona i senyor de Reus la segona. El paper de l'arquebisbe en tot aquest procés és prou evident ja que regula les diferents donacions fent ús de la seva potestat i de la seva jurisdicció. Un dels punts on es veu clara l'actuació del metropolità és precisament el repartiment que fa de la senyoria de Reus entre Bertran de

\footnotetext{
${ }^{20} \mathrm{Cfr}$. Emili Morera Llauradó, Tarragona cristiana, I, Tarragona, 1981. Josep M. FONT Rius, Entorn de la restauració cristiana de Tarragona. Esquema de la seva ordenació jurídica inicial, "Boletín Arqueológico", LXVI (Tarragona, 1966), pp. 83-105. F.Javier FACI LACASTA, Algunas observaciones sobre la restauración de Tarragona, "Miscel lània en homenatge al P.Agustí Altisent", Tarragona, 1991, pp. 469-485, essent aquest darrer treball una de les últimes aportacions al tema concret de la restauració de la seu metropolitana.

${ }^{21}$ Ezequiel GorT I JuANPERE, La Cambreria de la Seu de Tarragona, segles XII i XIII, Reus, 1990, p. 49. Cita la concòrdia $A d$ perennem per la qual s'arriba a un acord per a regular la forma de govern de la ciutat i del Camp de Tarragona.

${ }^{22}$ Ezequiel Gort JuANPERE, Dels origens al 1714, dins de P. ANGuera; E. Gort; J. MÈlich, Aproximació a la història de Reus, vol. 1, Reus, 1984, pp. 18-20.
} 
Castellet i la totalitat del Capítol, encara que més endavant va passar al cambrer, dignitat capitular que tenia com a missió el proveir el vestuari als canonges. Les rendes per a aquesta provisió provenien del patrimoni de Sant Fructuós que estava format per Reus, Castellvell, Almoster i Vila-seca, a més d'algunes possessions a l'horta de Tarragona ${ }^{23}$.

La relació entre Reus i l'arquebisbe és doncs prou evident, però ja no ho és tant a l'hora de parlar del notariat $i$ del seu funcionament. La documentació és ben escassa, per la qual cosa no podem fer sinó esbossar algunes hipòtesis que ens fan partir, en un primer moment, de les prerrogatives que tenia l'arquebisbe al Camp.

En virtut d'un d'aquests drets, en contra del rei, l'arquebisbe podia crear notaris, escrivans, batlles, procuradors i altres funcionaris, encara que la referència que en tenim és, almenys en el treball que ho esmenta, bastant més tardana que el període que ara treballem ${ }^{24}$. D'entrada hem de pensar que la notaria de Reus entrava dins de les concessions del prelat metropolità. Però a més partim de la base de que tabel-lionat i estament eclesiàstic van estar estretament lligats al llarg de l'Alta Edat Mitjana, un clergat que tenia el monopoli de l'escriptura i que, com a tal, està facultat per a redactar les escriptures dels veïns que volen tancar un contracte determinat ${ }^{25}$. Aquesta qüestió ens fa establir una hipòtesi i pensar que la notaria de Reus forma una unitat amb la parròquia local, propietat de l'arquebisbe ${ }^{26}$.

Dins de la història del notariat cal recular fins al segle XII per a trobar precisament el moment en que comencen a desaparèixer els escrivans altmedievals, majoritàriament membres de la clerecia, i van sorgint molt lentament els notaris, canvis que es produeixen primer a Itàlia on es passa ja del simple scriptor al notarius publicus ${ }^{27}$. Aquest necessita d'una autoritat

\footnotetext{
${ }^{23}$ Per a la qüestió de la senyoria de Reus en mans del cambrer és fonamental el treball d'Ezequiel GORT JUANPERE, op.cit., 1990.

${ }^{24}$ Francesc CORTIELla OdENA, Una ciutat catalana a darreries de l'Edat Mitjana: Tarragona, Tarragona, 1984, p. 20.

${ }^{25}$ Félix DURÁn Cañameras, Idem, pp. 75-76.

${ }^{26} \mathrm{De}$ fet, l'arquebisbe va ser senyor de Reus fins la creació de la Cambreria, moment en que passà a ser-ne senyor directe ja que la vila va ser donada al cambrer del Capítol tarragoní tenint el primer cambrer documentat l'any 1173. Més endavant fou aquest mateix dignatari qui ostentà la senyoria directa quan l'arquebisbe Ramon de Rocabertí va traspassar el domini directe al cambrer Ramon de Sant Llorenç a l'any 1203. No obstant encara el prelat metropolità es va reservar per a ell la senyoria eminent. Cfr. Ezequiel GORT JUANPERE, op.cit., 1990, pp. 50-55; 75-76.

${ }^{27}$ José BONO HUERTA, op.cit., I, 1, Madrid, 1979, pp. 174-178.
} 
superior que li confereixi la fides publicam per a poder validar els instruments segons els nous corrents jurídics, documents que passen de la charta a l'instrumentum publicum. I a Catalunya es dóna una transició, qualificada de lenta, ${ }^{28}$ que afecta tant la persona del notari com l'objecte de l'instrument. I en aquests moments qui té poder per a crear notaris és el rei, juntament amb altres poders com els barons jurisdiccionals, l'Església -en el cas que ens ocupa, l'arquebisbe- i els municipis ${ }^{29}$. Pel que fa a l'Església hi ha un tipus d'escrivanies parroquials depenents d'institucions religioses, com ara la de Reus que depenia de l'arquebisbe de Tarragona almenys des de 1284 , segons algun autor ${ }^{30}$. No obstant pensem que cal anar més enrera per a veure qui té el poder de concedir la notaria de Reus i a qui pertany. Tenint en compte els antecendents en tot el que fa a la jurisdicció episcopal sobre el Camp podem apuntar que l'escrivania reusenca depèn del metropolità, com també la majoria de notaries de la rodalia, i fins i tot les de gran part de les parròquies de la diòcesi ${ }^{31}$.

D'entrada però, sabem de cert que la notaria estava en mans del rector de la parròquia ${ }^{32}$. Aquest, diu Duran, la va recuperar l'any 1283 arrel de la pugna entre el notariat laic i l'eclesiàstic que hi ha en aquells

\footnotetext{
${ }^{28}$ Josep M. PONS GURI, op.cit., (1990), p. 97.

${ }^{29}$ Rafael Conde I Delgado DE Molina, op.cit., 1994, pp. 442-456. També Ignasi J. BAIGES JARDí, El notariat català: origen $i$ evolució, "Actes del I Congrés d'Història del Notariat Català", Barcelona, 1994, pp. 142-143. A les àrees rurals molts notaris eren de creació abacial $\mathrm{i}$ a les seus episcopals hi havia els notaris de les cúries com els que es nomenaven per a llocs de jurisdicció eclesiàstica.

${ }^{30}$ Rafael Conde I Delgado De Molina, Ibídem, 1994, pp. 452-453. També depenien de l'arquebisbe les escrivanies de Valls i Constantí. Conde cita el treball de Victorino SANTAMARÍA, Idem, pp. 23-24 i 30-34, que a la vegada ens remet a A. BOFARULl I Brocà, Anales históricos de Reus desde su fundación hasta nuestros días, el qual afirma que l'any 1284 el rector tenia al seu càrrec la notaria pública, en la qual hi treballaven també escrivans, que signaven els documents però sempre anaven acompanyats per l'autorització del rector. Nosaltres utilitzem l'edició de 1961, en la que, en el volum 2, p. 70, ens dóna aquesta notícia. Igualment fa referència a aquest darrer autor Josep M. GUIX SUGRAÑES, El Llibre de la Cadena, vol.1, Reus, 1963, pp. 82-83.

${ }^{31}$ Hipòtesi que ens vé avalada per la gran quantitat de protocols notarials que es guarden a l'Arxiu Històric de l'Arxidiòcesi de Tarragona, sèries que comencen amb l'esmentat manual d'Alcover però que, per al segle XIII $i$ des de ben aviat apareixen també a Ciurana, La Selva del Camp, Guàrdia dels Prats, Maldà...Els manuals procedeixen de les escrivanies parroquials de la diòcesi tarragonina.

${ }^{32}$ Félix DURÁn CAÑAmeras, Idem., p. 119.
} 
moments ${ }^{33}$. I és que el xoc entre la tradició del clergat i les ambicions del rei s'escalfà quan l'any 1281 ordenà als titulars de l'administració dels districtes iniciar una investigació sobre el funcionament de les escrivanies ${ }^{34}$. Com a conseqüència d'aquesta inquisició moltes oficines van anar a parar en mans de laics, atorgant el propi rei algunes escrivanies tot imposant la seva autoritat $\mathrm{i}$ el seu poder, arribant també a activar una nova normativa. Després uns delegats del monarca continuaren assignant escrivanies fins l'any 1283 , moment en que es trobà la solució a les Corts, procedint a la devolució general d'escrivanies als rectors ${ }^{35}$, moment al qual es refereix Durán Cañameras per a la notaria de Reus.

A partir d'aquesta sortida al problema l'oficina de Reus va tornar a mans del rector, tal com amb tota seguretat havia estat des dels incis, i depenent de l'arquebisbe, tot i que els primers documents que analitzem no ho acaben de precisar. Per exemple, i dins del procés d'implantació del notariat públic a Reus i per a veure precisament les seves primeres passes anem a parar a les dues cartes de població on ja trobem consigants els noms dels personatges que validen els documents. En la primera carta, atorgada per Bernat de Bell-1loc l'any 1183, hi ha el signe de Bernardi, levita, qui hoc scripsit cum literis dampnatis in .X. linea et in .XV. propter mandamentum Petri de Barberano QUO SUPR.A. L'escrivà delata clarament la seva condició d'eclesiàstic per la qual dóna fe de l'acte. No obstant sembla que aquest actua per autoritat de Pere de Barberà, del qual no es diu ni la condició ni

\footnotetext{
${ }^{33}$ El tema de les concessions d'escrivanies i notaries ha estat estudiat per diversos autors que recullen els documents referents a aquestes qüestions, com ara la prohibició sorgida de les Corts d'Osca l'any 1247 per la qual s'impedeix que els clergues exerceixin com a notaris, almenys a l'Aragó. Remetem als principals treballs que tracten tant la creació i concessió de notaries com els conflictes sorgits per l'enfrontament entre els clergues que actuen de notaris i el poder del monarca que, poc a poc es vol anar obrint camí i incorporar el notariat a les seves regalies Rafael CONDE, La titularidad de las notarías parroquiales catalanas desde Pedro II el Grande Jaime II: del proyecto de Besalú (1281) a la Pragmática de 1302), "Estudis sobre la història de la institució notarial a Catalunya", Barcelona, 1988, pp. 31-32. Rafael CONDE; Francisco GIMENO, Notarías y escribanías de concesión real en la Corona de Aragón (s.XIII), "Notariado público y documento privado", València, 1989, pp. 281-329. Antoni M. ARAGó CABAÑAS, Concesions reials del dret de notariaa a parròquies $i$ monestirs catalans (segles XII $i$ XIII), "EHDAP", VI(1978), pp. 1-14. Per al segle XIV, com a continuació dels conflictes iniciats la centúria anterior hi ha dos treballs de M. Teresa FERRER MALLOL, op.cit., (1977), pp. 19-34 L'expansió, op. cit, (1995), pp. 55-73. Josep M. PONS GURI, El conflicte de la notaria de Girona, "Reculls d'estudis d'història jurídica catalana", vol. 1, Barcelona, 1989, pp. 33-93.

${ }^{34}$ Cfr. Francesc CarReras CANDI, Idem, doc. XI, p. 350.

${ }^{35}$ Rafael CONDE, op.cit., 1988, pp. 35-41.
} 
el càrrec que ostenta ${ }^{36}$. Aquest document, en definitiva, ens demostra que encara no ha arribat a Reus la figura del notarius publicus, personatge que tardarà molts anys en fer-se present en els documents tal com veurem més endavant, però que en altres indrets de Catalunya ja ha començat a validar instruments amb la fe pública ${ }^{37}$.

Tres anys més tard, el cambrer de la Seu de Tarragona, Joan de Sant Boi, concedeix la seva carta de població, dualitat respecte la de l'any 1183 que ens posa de manifest la singularitat de la senyoria a Reus, i si es vol també al Camp. Ara ja trobem una diferència en relació a l'anterior, encara que el notari no sigui de Reus sinó de Tarragona ${ }^{38}$. Diu així el document: Ego, Petrus de Manlevo, hoc scripsi mandato Petri de Terrachona, Terrachone notarii ${ }^{39}$. La variació és ben evident ja que ara tenim un escrivà que redacta el document i ho fa per manament del notari, del que és obtentor de la notaria. És aquest, en Pere de Tarragona, qui realment dóna fe pública del contingut de la carta de població. No obstant aquest segon instrument ens dóna idea del funcionament del notariat a Tarragona, potser a la cúria episcopal o de l'entorn del capítol, però no ens aporta informació respecte de l'escrivania de Reus. Per altra banda ens demostra com a la ciutat metropolitana hi ha una certa estructura més evolucionada de la institució notarial del que hi pugui haver a la petita vila de la que n'és senyor el cambrer.

Malgrat tot són indicis de l'existència d'un incipient notariat, encara que no amb les característiques del notariat públic. Aquest es desenvolupa a Reus al segle XIII arribant a la consolidació a finals d'aquesta centúria. Ens ho demostra la documentació que genera la seva pròpia activitat i que forma el conjunt de protocols notarials de l'Arxiu Històric Comarcal de

\footnotetext{
${ }^{36}$ Ezequiel GORT, Reus, 800 anys de les cartes de població, 1986, pp. 8-11. En aquest treball es publiquen els textos transcrits de les dues cartes de població juntament amb els pertinents comentaris que les contextualitzen.

${ }^{37}$ Honorio García, El notariado de Vich durante la Edad Media, "La Notaría" (Barcelona), (1947), p. 76. Ja l'any 1135 Pere de Redorta, bisbe de Vic i senyor jurisdiccional de la ciutat va concedir la notaria pública a Ramon de Lió. Félix DURÁn CAÑAMERAS, Ibídem, pp. 71-73. L'any 1188 el rei Alfons el Cast establia al clergue Bernat l'escrivania pública de Vilafranca del Penedès.

${ }^{38}$ Ezequiel GORT, op.cit., 1986, pp. 12-17.

${ }^{39}$ Aquilino Iglesia FERREIRós, Ibídem, p. 146. Documenta aquest notari en diversos instruments publicats, on apareix amb subscripcions similars a la de la carta de població de Reus però que en qualsevol cas denoten la seva condició de notari en transició cap a la nova figura del notari públic.
} 
Reus. Juntament a aquest volum de fonts també hi ha un nombre important de pergamins anteriors al segle XIV, que revisem exhaustivament.

\section{1. Els notaris $i$ els escrivans}

Les dades que ens ofereixen els documents no són el suficientment generoses com desitjariem però ens deixen entreveure el caràcter dels notaris, la seva funció i, sobretot, quina és l'autoritat que els ha concedit el càrrec. També ens donen una mostra de l'evolució de la figura del notari, de la lenta transició cap al notariat públic per influència de la doctrina notarial sorgida a Bolonya.

El perquè encara ens trobem amb un notariat diluï a la dotzena centúria no és un problema exclusiu sinó que s'emmarca dins de l'evolució que sofreix la institució en aquests anys. Recepció del Dret Comú i dels nous usos notarials són encara elements que es van incorporant poc a poc a Catalunya, així com l'aparició de les primeres escrivanies públiques ${ }^{40}$. El renaixement del notariat és encara incipient i és precisament entre els segles XII i XIII que s'adapta el nostre sistema notarial als usos itàlics influenciat precisament pel ius commune. Els canvis es noten tant en la institució com en el document, que passa de la charta altmedieval a l'instrumentum publicum, seguint els passos de redacció que segueixen ja els notaris bolonyesos ${ }^{41}$. L'antic scriptor es transforma en notari públic, aquell que dóna fe pública del contingut del document, una fe que li vé conferida per una autoritat superior.

Dins de l'engranatge i de l'estructura de la notaria de Reus fem un repàs a la nòmina dels notaris que tenim localizats. A partir del llistat podem copsar la transformació i evolució de la pròpia institució, sobretot pel que fa a l'aparició del notariat públic. Vèiem més amunt com tenim alguns indicis de funcionament d'una escrivania a finals del segle XII, amb la redacció de la carta de població per part d'un levita. No obstant cal que anem al segle XIII per a trobar la majoria de pergamins que ens donen més dades sobre aquesta evolució i implantació.

\footnotetext{
${ }^{40} \mathrm{Cfr}$. Ignasi BaIGES I JARDí, Ibídem, pp. 134-140.

${ }^{41}$ Josep M. PONS GURI, op.cit., (1993), pp.29-32.
} 
L'any 1205 , en un document traslladat l'any $1563^{42}$, hi ha la subscripció de Gerard, presbiter, notarius publicus Reddis, hec (Signe) laudo, acompanyat de Berenguer, subdiachoni qui hec scripsit mandato Raymundi Tarracone Camerarii. Sembla doncs que a Reus hi ha una notaria en funcionament, a càrrec d'un prevere, encara que el document el redacta un altre eclesiàstic, el subdiaca Berenguer, per manament del cambrer Ramon de Sant Llorenç ${ }^{43}$. El document és una concòrdia per la qual Bartomeu d'Almoster passava a tenir pels Bell·lloc les dues terceres parts del terme d'Almoster que pertanyien a la castlania. Tractant-se d'un trasllat hem de dubtar de la subscripció de Gerard, qualificat aquí de notari públic de Reus, títol que sembla prematur ja que no el tornarem a trobar en altres instruments validats per aquest tabel $\cdot \mathrm{lió}^{44}$.

El mateix any de 1205 trobem un notari Gerard signant el testament de Guillema, muller de Pere Ferrer. És un document original però en la subscripció no diu si és notari de Reus i, a més, el signum és diferent del que trobem, traslladat, en l'instrument anterior. Igual que en aquest ara també ens indica que és prevere i que redacta el testament mandato Raimundus Camerarii Terrachone ${ }^{45}$. No sabem si es tracta de la mateixa persona encara que sí podem copsar que, qui realment dóna autoritat al notari és el cambrer, que en aquest moment ja és senyor directe de Reus.

Del prevere Gerard en tenim la primera notícia en un establiment que Ramon de Sant Llorenç atorga a favor de Pere Cirera, al mes de gener d'aquest mateix any de 1205. Segons algun autor aquest clergue era a la vegada rector de la parròquia de Sant Pere de Reus, atribució que no apareix

\footnotetext{
${ }^{42}$ AHCR, Castlans, 3. 1205, febrer, 25 (trasllat 1560, febrer, 17). Citat per E. GoRT, op.cit., 1990, p. 81. D'aquest document ja es va fer una primera còpia a l'any 1293 a càrrec del notari tarragoní Miquel Boter. (Quan fem referència a pergamins situem al costat de la sigla AHCR el nom de la carpeta on està conservat el document concret a què ens referim). 19-20.

${ }^{43}$ Va ocupar la Cambreria fins a l'any 1208. Ezequiel GORT I JUANPERE, op.cit., 1989, pp.

${ }^{44} \mathrm{Cfr}$. Aquilino Iglesia Ferreirós, Ibidem, pp. 106 ss. Presentant les pautes de recerca per a la difusió del Dret Comú, a les que hem fet referència més amunt, es centra en les fonts que es poden utilitzar per a la investigació suggerint l'estudi de documentació publicada. No obstant posa algunes limitacions de la que destaquem el fet que moltes edicions de textos es basen en còpies $\mathrm{i}$ trasllats en els quals, malgrat seguir amb fidelitat el contingut del text original, incorporen titulacions que no hi figuraven en el document primitiu on en suprimeixen d'altres.

${ }^{45} \mathrm{AHCR}$, Àpoques, censals i almoines, 2. 1205, abril, 11.
} 
en l'establiment a què ens referim, on tan sols apareix anomenat com a Geraldus clericus ${ }^{46}$.

Avançant en la centúria, l'any 1235 trobem una altra subscripció en la que hi manca encara el qualificatiu de notari. Tan sols hi ha el nom de la persona que redacta l'instrument per manament d'un altre, en Pere Borrell. Aquest és segurament el que té el càrrec de notari tal com suposem a partir de la presència del seu signe al peu de l'instrument, un signum elaborat i guarnit, diferent del de l'escrivà Constantí. Aquest escrivà que acompanya la seva rúbrica amb les corresponents esmenes al text. En el document no hi ha constància del lloc on s'atorga el document la qual cosa ens deixa el dubte si els suposats notari i escrivà són de l'escrivania de Reus ${ }^{47}$. El que sí que es desprén, almenys a nivell metodològic, és la manca de dades sobre el notariat reusenc i l'escrivania local. Com podem constatar en la primera part del segle XIII encara són molt poques i apareixen bastant distanciades entre elles. No és fins al 1240 que trobem un Berenguer Conesa que redacta el document per manament del mestre Ramon, capellà de Reus ${ }^{48}$. Podem constatar com l'escrivania està vinculada a la parròquia o que almenys el clergat n'ostenta la titularitat, afirmació que mantenim per a uns anys més tard quan tornem a trobar que Ramon, capellani de Reddis mana fer un instrument a Pere d'Aula Vella ${ }^{49}$. Possiblement el capellà el capellà és el titular de l'oficina i l'altre és l'escrivà, matisos que no fan més que indicarnos que el notariat públic encara és quelcom que s'està gestant i que ens planteja encara alguns interrogants.

\footnotetext{
${ }^{46} \mathrm{AHCR}$, Cambrers, 26. 1205, gener, 5. Citat per E. GoRT, op. cit., 1990, pp.85-86. Es tracta d'un solar per a construïr-hi una casa per a que la tingui pel cambrer, salvant sempre la fidelitat a l'església de Tarragona. El cens estipulat és de 4 sous per Sant Miquel. A partir de l'establiment GORT apunta breument les dades que ens facilita aquest document $\mathrm{i}$ els altres que segurament es van fer a Reus en aquests moments. Sobretot es centra en la informació que ens aporten els noms, dels quals destaquem el prevere Gerard, que redactà el document per manament pel cambrer Ramon. GORT cita aquí el treball de J. M. DOMINGo, La prioral de Sant Pere de Reus, Reus, 1977, p. 13 en el que es diu que el clergue Gerard és el rector de la parròquia, atribució poc fonamentada per la manca de documentació. També J.M. GUIX SUGRAÑES, Ibídem, p. 83, diu que Gerard era rector de Reus l'any 1204, i signava documents gràcies a la seva condició d'eclesiàstic.

${ }^{47} \mathrm{AHCR}$, Almoines, 1. 1235, agost, 5. Pere Borrell signa el pergamí amb un signe notarial, elaborat $\mathrm{i}$ guarnit, diferent del de l'escrivà Constantí.

${ }^{48}$ AHCR, Particular, 1. 1240, setembre, 25. Es tracta del testament de Pere Cirera en el que cita el mestre Ramon entre el llistat dels que reben algun llegat.

${ }^{49} \mathrm{AHCR}$, Particular, 2. 1244, febrer, 4. És una donació inter vivos atorgada per Raimunda, muller del difunt Pere Cirera a favor del seu fill Guillem. L'objecte és una casa que té a Reus, amb un hort $\mathrm{i}$ arbres.
} 
Una vintena d'anys són suficients per a començar a trobar una resposta a totes aquestes qüestions, i és que a l'any 1264 ja trobem un altre rector de la parròquia i que, a més, hi ha un notari. Guillem de Pont és notario de Reddis pro Raimundo de Ilice, rectore eiusdem ecclesie hoc scripsi die et anno... ${ }^{50}$.

L'any 1275 és rector Ramon d'Olivella i hi ha un notari que és Jaume de Teres $^{51}$. És curiós com al mes d'agost d'aquest mateix any trobem un altre notari, Pere Pastor, un escrivà, Alexandre de Bonmacip, i en Ramon de Puig com a rector. L'escrivà és scolarius i escriu el document iussu Petri Pastoris notarius publicus de Reddis. Veient ja aquesta subscripció podem adonar-nos de la transformació que s'ha donat en la institució notarial local. El notari és públic, adjectiu que no haviem trobat encara en cap dels documents que hem repassat fins ara. Al mateix temps Pere Pastor, sacerdot, és notarius publicus de Reddis pro Raimundo de Podiolo, rectore eiusdem loci. Per tant, ara sí que podem afirmar que el titular de la notaria és la parròquia, en la persona del rector, però el càrrec de notari l'ostenta un altre, en aquest cas un prevere que té al seu servei un escrivà ${ }^{52}$. Un any més tard, amb Ramon de Pujol com a rector, hi ha un altre notari públic de Reus que és Pere Colom ${ }^{53}$.

Cal anar a l'any 1281 per a trobar un nou escrivà, Joan Soguer que subscriu l'instrument per manament del notari Pere Colom que, en els dos documents que hi ha d'aquest any, és qualificat només de notarius ${ }^{54}$. Això ens porta a pensar en l'ambigüitat dels termes encara que no necessàriament ens condueixi a dubtar de la implantació del notariat públic. Aquesta implantació, si bé encara no és definitiva, sí que es troba en un moment de

\footnotetext{
${ }^{50}$ AHCR, Religiós, 3. 1264, juny, 12. En aquesta mateixacarpeta, n.2, un document datat un mes després (1264, juliol, 14), trobem aquesta subscripció: "Ego Guilelmus de Ponte, notarius de Reddis pro Raimundo de Ylice, rectore eiusdem ecclesie hoc scripsi mandato eiusdem rectois predicti cum literis superpositis in $\mathrm{V}$ linea, ubi dicitur et sucersores et in alio loco, in eadem line II dicitur patris, et hoc Signum (Signe) feci".

${ }^{51} \mathrm{AHCR}$, Religiós, 6. 1275, juny, 17. "Ego Iacobus de Teres, notarius Redis, hoc escripsi iussu Raimundi de Olivella, rectoris ecclesie dicti loci, et hoc (Signe) feci".

${ }^{52}$ AHCR, Religiós, 5. 1275, agost, 20.

${ }^{53}$ AHCR, Religiós, 7. 1276, novembre, 11. "Sig (Signe) num Petri Columbi, notarius publicus in villa Rediis qui hoc scripsit mandato Raimundo de Podiolo, rectoris eiusdem loci die et anno prefixis".

${ }^{54}$ AHCR, Particular, 5. 1281, abril, 23; AHCR, Religiós, 8. 1281, juliol, 29. (Tresllat: 1281, agost). El trasllat està fet pel mateix escrivà Joan Soguer i comprovat per Pere Colom, notarius in Reddis per Raimundum de Podiolo, rectorem eiusdem loci.
} 
transició. I sembla consolidar-se més endavant quan, a partir de l'any 1285 , trobem sempre ja el càrrec de notari públic acompanyant el nom del validador del document. Aquest any encara és notari el ja citat Pere Colom $^{55}$, ajudat en les tasques de l'oficina per "Raimundus de Ylice, scolaris qui hoc scrpisi mandato Petri Columbi, notarius publicus in villa de Redis per Petrus de Belvís, rectorem eiusdem loci", el qual redacta i signa només un dels dos documents d'aquest any ${ }^{56}$. No podem assegurar si aquest Ramon és el mateix que citavem més amunt i que era rector de la parròquia de Reus l'any 1264. En tot cas els qualificatius que acompanyen ambdues subscripcions són clars $i$, en un principi no deixen lloc al dubte.

Joan Soguer és escrivà però sabem que ascendeix a notari almenys des de $1291^{57}$. El rector continua essent Pere de Bellavista. El funcionament de la notaria de Reus s'estabilitza i s'aclareixen les denominacions i titulacions de cadascú, encara que només trobem aquest notari com a validador dels documents $i$ un escrivà, Berenguer Ferrer, a l'any $1300^{58}$. Per un altre document que hem consultat sabem que Joan Soguer era mort a l'any 1307 , ocupant la notaria Ramon Peiró, notari públic de Reus pel rector Bellavista ${ }^{59}$.

\section{ELS MANUALS NOTARIALS}

Hem pogut copsar ja quin és el funcionament de la notaria de Reus, almenys a nivell de persones, i és ara l'hora de veure'n la seva producció. És evident que els pergamins als que ens hem referit són importants com a

\footnotetext{
${ }^{55}$ AHCR, Particular, 8. 1285, gener, 8.

${ }^{56}$ AHCR, Particular, 7. 1285, gener, 30.

${ }^{57}$ Citem només un pergamí de l'AHCR, Castlans, 5. 1291, desembre, 5. No obstant encara hi ha 7 pergamins més que estan validats per aquest notari.

${ }^{58} \mathrm{AHCR}$, Particular, 16. 1300, gener 28. És el darrer pergamí que pertany cronològicament al segle XIII i en el que apareix l'escrivà Berenguer Ferrer, "qui hoc scripsi iussu Iohannis Soguer, notarius publicus de Reddis".

${ }^{59}$ AHCR, Particular, 14. 1299, abril, 26. (Trasllat: 1307, desembre, 12). Es tracta de l'inventari dels béns del difunt Jaume Cirer que fa fer la seva mare, Maria, muller del difunt Guillem Cirer i tutora i curadora de Maria, filla de Jaume. Per sí mateix no presenta cap particularitat excepte en el moment en que cita diversos instruments que hi ha a la casa inventariada. Entre ells destaca "unum instrumentum composicionis facto inter dictum lacobum Cirer et Marie filie sue et Guilelme uxoris sue ex una parte, et Belrís, uxore quondam Bernardus Gener, ex altera, divisum per $A B C$, quod incipit 'Noverint universi quod cum questione' et finit' di et anno prefixis'".
} 
mostra de l'activitat de l'oficina i dels notaris ${ }^{60}$, però és tal vegada en els protocols notarials on es pot percebre millor tot el volum de treball, la forma de confeccionar els llibres, la pròpia redacció, així com la introducció dels nous usos notarials que arriben de Bolonya ${ }^{61}$.

\section{1. Característiques externes}

A Reus es conserven pocs protocols notarials del segle XIII i un dels quals, per diverses circumstàncies, es troba guardat al Museu Comarcal Salvador Vila-seca. Aquest volum està datat l'any 1292 i per raons d'accés, de moment, no l'hem consultat. La resta s'inicien l'any 1297 arribant al total de 3 volums fins a l'any 1300. El primer volum és dels anys 1297-98, el segon és de l'any $1300 \mathrm{i}$ el tercer sembla que és de l'any 1300 ó $1301^{62}$. L'estat de conservació d'aquest grup és bastant dolent ja que tots ells presenten taques d'humitat i forats provocats per l'acció dels insectes, efectes que dificulten en gran mesura la lectura i el correcte enteniment de les notes i el seu contingut.

El tamany dels llibres és el foli i cap d'ells conserva la coberta de pergamí. En general també estan mancats dels primers fulls o, en altres casos, aquests estan afectats per la humitat. Això fa que no puguem saber qui és l'autor de cap d'ells. Passant a l'interior la primera cosa que cal notar és el fet de que la caixa d'escriptura és pràcticament inexistent i que el text

\footnotetext{
${ }^{60}$ Jean L. LAFFONT, Introduction. Problèmes et enjeux de l'analys historique de l'activité notariale, "Problèmes et méthodes d'analyse historique de l'activité notariale (XVe-XIXe siècles)", Toulouse, 1991, pp. 17-28. D'entrada distingeix entre pràctica notarial i activitat notarial, essent la primera l'exercici de la professió del notari i considerant la segona com el volum de treball i clientela que rep el notari, qüestió aquesta que es reflecteix perfectament en els protocols. L'altra accepció, la de la pràctica notarial, està més lligada, segons aquest autor, a la Història del Notariat i la seva evolució. En tot cas ho tenim en compte a nivell d'orientació.

${ }^{61}$ Per les característiques dels llibres notarials vegeu Josep M. PONS GURI, op.cit., (1990), pp. 97-109; Algunes orientacions per a la utilització dels fons de seccions històriques en districtes notarials, "Reculls d'estudis d'història jurídica catalana", vol.1, Barcelona, 1989, pp. 159-190; Caracteristiques paleogràfiques, op. cit., "Reculls", vol. 1, Barcelona, 1989, pp. 191218. Pere PUig Ustrell, Ibídem, vol. 1, pp. 18-33. Rafel Ginebra I Molins, Ibídem, pp. 1635 .

${ }^{62} \mathrm{Per}$ raons de metodologia $\mathrm{i}$ de tractament informàtic els hem assignat un codi que no es correspon amb el complex sistema de catalogació de l'Arxiu, que no individualitza cada llibre sinó per capses i lligalls. Els codis són els següents: R1, R3-4, R5-6.Cal dir que aquest darrer volum està dividit en dos quaderns i considerat com a dos unitats separades en el catàleg. Seguint la datació podem comprovar amb prou seguretat que formen un sol llibre que, per raons diverses, s'ha descosit i ha perdut la unitat inicial.
} 
ocupa quasi la totalitat del foli, tant que, en els casos en els que la humitat s'ha menjat el paper ha desaparegut gran part del text dels marges. Tampoc no hi ha una excessiva separació entre les notes sinó, al contrari, en moltes ocasions no es pot notar quan comença una nòtula i quan acaba l'altra. Aquest breu espai és aprofitat per l'escrivà per a inserir la data de l'instrument o alguna altra anotació.

La data no la trobem en cada nota sinó només en algunes i generalment sempre apareix sencera. Sempre hi ha el mes i el dia, seguint el sistema de la calendació, i situat al mig del full o a un costat, generalment el dret. En molt poques ocasions hem trobat la datació completa, incloent l'any, referències que apareixen en els tres manuals que treballem. El primer llibre s'inicia al mes de desembre de 1297 i acaba pel mes de febrer. Entre els folis 14 i 17 hi ha un bifoli cosit posteriorment que és l'únic lloc de tot el manual on apareix la data sencera, indicant que es tracta de l'any 1298, lògicament de l'Any de l'Encarnació, la qual cosa ens fa sumar-hi un any més. Les notes d'aquest bifoli segueixen la datació correlativament pel que fa al mes i al dia, de manera que ens fa pensar, no sense algunes reserves, que l'any és el correcte.

En el segon manual, un llibre format per 40 bifolis $^{63}$, força gruixut i amb els primers folis molt deteriorats, s'inicia a les 12 kalendes de juliol, però aviat trobem la data sencera amb l'any i tot ${ }^{64}$. No serà fins més endavant que trobem el canvi d'any, de 1299 a $1300^{65}$, anotació que indubtablement ens situa correctament la cronologia d'aquest manual, iniciat l'any 1299 i que acaba l'any següent.

Finalment és el darrer manual, R5-6, el que ens porta més confusions a l'hora de datar. Trobem ja a l'inici la data sencera però no es veu correctament si es tracta de l'any 1301 o, en lloc de primo hi diu un altre $a^{6}{ }^{66}$. De fet més endavant hi ha alguna altra referència, en números

\footnotetext{
${ }^{63}$ Foliació actual en llapis que dóna com a resultat 80 folis.

${ }^{64} \mathrm{R} 3-4$, f. 26 v. "Anno Domini $\mathrm{M}^{\circ} \mathrm{CC}^{\circ} \mathrm{XC}^{\circ}$ Nono, pridie kalendas octobris". Després d'aquest foli hi ha un full de paper, plegat en forma de bifoli i sense cosir, que porta la mateixa data.

${ }^{65}$ Idem, f. 73 v. "Anno Domini $\mathrm{M}^{\circ} \mathrm{CCC}^{\circ}$ et septimo kalendas aprilis".

${ }^{66} \mathrm{AHCR}, \mathrm{R} 5-6, \mathrm{f}$. 1 . És un foli solt que està numerat amb el n. 1.
} 
aràbigs, com ara la que indica l'any 1307 , basant-se tal vegada en la data que hi figura en aquest full ${ }^{67}$. O també les que diuen $1300^{68}$.

Pel que fa a la confecció del document, amb totes les fases de redacció, notem que en els protocols reusencs s'indica la ferma mitjançant dues ratlles paral-leles i lleugerament inclinades a la dreta situades a sobre del nom dels atorgants. Amb aquestes línies es demostra que els interessats donen conformitat a l'atorgament. A vegades acompanya aquestes línies l'abreviatura $i u$. o la paraula sencera iurat/iuravit $t^{69}$, mot que expressa el jurament, inclòs també en algunes de les clàusules finals de la nota.

En la majoria de folis hi ha dues o més línies que barren de dalt a baix cada un dels assentaments, inclinades a la dreta i alguna vegada acompanyades també d'una creu aspada, i que són signe de que la nota ha estat posada in publicam formam i ha estat entregat el pergamí a les parts interessades. Quan aquest document presenta la modalitat de carta divisa s'anoten al marge les lletres $A B C^{70}$. Una variació de les línies a que ens referim són les que presenten formes ondulades, signe de que l'instrument ha estat inutilitzat. Al costat de les notes en les que trobem aquestes línies ondulants acostumen aparèixer anotacions marginals que indiquen la cancel-lació: Non venit ad perfeccionem. Ideo fuit cançellatus de voluntate pertium $^{71}$. L'assentament 4 d'aquest foli està resseguit amb una ratllat horitzontal al llarg de les sis línies que ocupa el text i també està acompanyat d'aquesta expressió a la que ens referim ${ }^{72}$. Finalment i dins del procés de redacció de l'instrument encara trobem expressions que denoten certes qüestions del sistema de confecció del document, com per exemple solvit per

\footnotetext{
${ }^{67} I d e m$, foli solt del darrera. Hi diu $M^{o} C C C^{o}$ et VII (forat) La part deteriorada devia de contenir la data sencera, amb el mes i el dia i segurament aclariria la datació correcta.

${ }^{68}$ Idem, f. 13 i f. $30 \mathrm{v}$.

${ }^{69}$ Maria Teresa Ferrer I Mallol, La redacció, op. cit., (1974), p. 44. Pensa que hi ha diferències entre els que només han fermat l'instrument $i$ els que, a més, han jurat o prestat homenatge, variacions que venen assenyalades per les ratlles i per l'abreviatura $i u$. J.M. PONS GURI, Algunes orientacions, op. cit., 1989, pp. 177-178.

${ }^{70}$ AHCR, Protocols notarials, R1, f. 18 v. Apareix tres vegades aquesta anotació, acompanyada de la indicació solvit.

${ }^{71}$ AHCR, Protocols notarials, R5-6, f. 21.

${ }^{72}$ AHCR, Protocols notarials, R1, f. 2 solt, f. 9 v. i f. 17 v. Hi ha la línia horitzontal que ratlla tot l'assentament, però per sota de la línia d'escriptura i deixant veure integrament el text juntament amb el text de cancel·lació, molt similar per als tres assentaments que citem aquí: "fuit cancellatus de voluntate partium, ex eo predicta venditio non transivit".
} 
notula III denarios (o també apareix amb II denarios) ${ }^{73}$. Més entenedora encara és aquesta ${ }^{74}$ : creditrix dixit quod non apartegat redigere in publicam formam et ideo remasi ad faciendam. I encara n'hi ha una altra que ens diu quelcom més, expressió que va emmarcat amb una orla bastant guarnida: usque sunt facta et redcta omnia instrumnta que fuerint de honoribus qui sunt in iurisdiccione Domini Camerarii ${ }^{75}$. La introducció dels nous costums dels notaris i de la nova estructura instrumental, amb el valor de l'instrumentum publicum és evident. Igualment hi ha certes anotacions que no són res més que qüestions directament relacionades amb el contingut de l'assentament, com ara qui Deum pauperes ipsos suos heredis universales instituit, en referència a una venda atorgada per Guillema, la muller del difunt Arnau Cau, legítima tutora i curadora dels seus fills. Es a favor de Guillem Borraces i el motiu de la venda és per a pagar deutes, segurament relacionats amb la darrera voluntat del marit traspassat i els llegats que allí va estipular. Per això hi ha aquesta anotación ${ }^{76}$.

Altres expressions que trobem en els marges o entre les notes són non solvit, solvit, debet que indiquen el pagament de les taxes notarials, els aranzels que paguen els rogataris a l'acudir a la notaria. A vegades van acompanyades de determinades quantitats. Aquests salaris no sempre apareixen en els llibres que treballem. Ocasionalment estan en els marges drets i emmarcats dins d'uns requadres amb línies bastants irregulars. Fins i tot en gran part dels folis podem observar una quantitat al final de la pàgina que no és res més que la suma dels diferents salaris que s'han satisfet per a cada instrument. Com a exemple hi ha dues ocasions en que aquesta quantitat queda suficientment explicada: Suma usque hunc Centum XX et I solidos et III denarios, anotació que apareix al centre del foli i a la part inferior, igual que la de la pàgina següent: Suma usque hunc $C X X$ solidos $^{77}$. En general les quantitats ressenyades oscil-len entre els 6 diners els 4 diners, encara que poden aparèixer altres xifres. Per exemple trobem ie al marge i acompanyant un debitori hi ha la quantitat de 2 sous, però

\footnotetext{
${ }^{73}$ Idem, folis solts de darrera.

${ }^{74}$ AHCR, Protocols notarials, R5-6, f. 4.

${ }^{75} \mathrm{AHCR}$, Protocols notarials, R1, f. $18 \mathrm{v}$.

${ }^{76} \mathrm{Idem}$, f. $17 \mathrm{v}$

${ }^{77}$ AHCR, Protocols notarials, R3-4, f. 47-47 v.
} 
una mica més endavant $\mathrm{i}$ amb un mateix tipus documental, hi ha 10 diners $^{78}$. En referència als salaris notarials l'any 1241 l'arquebisbe de Tarragona, Pere d'Albalat, ja va fixar precisament les taxes que s'havien de cobrar per validar determinats documents, en virtut de les seves atribucions com a senyor del Camp i de la ciutat de Tarragona ${ }^{79}$. No obstant dubtem si ho podem aplicar a la notaria de Reus ja que es dirigeix als preveres de la ciutat de Tarragona, però sí que veiem clar quina és l'autoritat que concedeix les notaries i qui n'ostenta la titularitat.

A part d'aquestes anotacions marginals relacionades amb el procés de confecció del document notarial n'hi ha d'altres que no són tan transcendents i que ens donen notícies paral-leles al propi contingut de les notes. Ens referim, per exemple, a les proves d'escriptura i de tinta, que en la majoria dels casos reflecteixen fórmules del propi manual. Les més freqüents són, Notum sit ${ }^{80}$, Notum sit cunctis $^{81}$. També en una altra ocasió trobem el dibuix d'un cap humà, vestit amb una caputxa i acompanyat de l'expressió Salve Sanctu Christi ${ }^{82}$. No és aquest l'únic dibuix que hem localitzat entre els folis dels protocols que treballem. Una mà al costat d'una nota, al marge lògicament, indica que aquella nota és important o que presenta una certa rellevància ${ }^{83}$. O dibuixos amb formes que recorden més o menys escuts ${ }^{84}$,

${ }^{78}$ Idem, f. 3-3 v. En el cas del segon debitori hi ha, a més, l'anotació "solvit fuit debitis et ideo fuit cançellatus de voluntatis creditoris".

${ }^{79}$ Arxiu Històric de Tarragona, Pergamins, Calaixera 2, Calaix 16, perg. 1. 1241, gener, 18. Tarragona. "...ordinamus quod in Terrachonensis civitate notari recipiet pro carta debiti sex denarios, pro carta sponsalicium, si notetus in scribania ne extra tabellionem oporteat laborare decem et octo denarios. Si uno tabellionem me oportuint ad alium locum pro circa sponsalicii facienda, reciiat inde duos solidos in hoc casu. Pro testamenti, tres solidos, et non amplius e singulis predictorum ni si forte scripture ac laboris quantas ... et notarium plus recipere de predictis quod quidem ordinationem fieri volum ad pactam. (...)"

${ }^{80}$ AHCR, Protocols notarials, R5-6, f. 9 i 10 v

${ }^{81}$ AHCR, Protocols notarials, Idem, f. 12.

${ }^{82}$ AHCR, Protocols notarials, R3-4, f. 42. En aquest mateix manual, f. 11, trobem també unes formes humanes no tan perfeccionades com a la que aquí ens referim. Són tres formes de cap de persona molt estilitzades i que van acompanyades per inscripcions que podrien ser molt bé proves de ploma o divertimes del propi escrivà: "Quicumque male salvus. Quoniam nullus".

${ }^{83} \mathrm{AHCR}$, Protocols notarials, R1, f. 4.

${ }^{84} \mathrm{AHCR}$, Protocols notarials, R1, f. 16 v. Presenta una forma d'escut però dibuixat a base de puntets, no pas amb línies. També a R3-4, f, $12 \mathrm{v}$, hi ha dos escuts, un completament en blanc el seu interior i l'altre ple de línies horizontals; al f. 15 hi ha un escut amb barres verticals $i$ molt guarnit tot el seu entorn; encara al f. 23 trobem altres dos escuts amb característiques similars als que aquí ens referim. 
figures animals ${ }^{85}$ o formes geomètriques amb certes pretensions decorati$v^{8}{ }^{86}$. En ocasions és dins d'aquests marcs ornats que trobem les inscripcions a les que ens hem referit més amunt o altres més suggerents. Per exemple hi ha l'expressió Dominus dixit emmarcada amb una orla per la part esquerra $^{87}$, amb un significat que altres autors no han pogut interpretar a partir del que han trobat en altres manuals ${ }^{88}$. Segurament forma part dels exercicis escriptoris previs a l'escripturació, exercicis que no pretenen res més que provar la ploma.

El tipus d'escriptura amb que estan escrits aquests manuals és la típica gòtica notular utilizada en les oficines notarials de l'època. Es un lletra que en ocasions tendeix a una cursivitat exagerada, que dificulta en gran mesura la lectura correcta del contingut de les notes i que desfigura completament l'estructura de les lletres reduïnt-les a simples traços. No obstant, i estudiant amb deteniment els manuals, observem la presència clara de dues mans que participen en la seva confecció. Una és aquesta que fa una lletra molt minúscula, amb un ductus que en ocasions resulta excessivament ràpid, provocant una lletra molt cursiva $\mathrm{i}$ amb molts enllaços. Per contra, la segona mà fa una lletra molt sentada, gens inclinada, amb pocs nexes $\mathrm{i}$ arrodonida. Es molt més entenedora que l'anterior, més gran i amb un contrast més evident entre els traços gruixuts i prims.

En general abunden les abreviatures, sobretot les realitzades per suspensió, tant que s'arriben a substituïr paraules senceres per la primera lletra. També algunes frases o clàusules queden reduïdes a la primera lletra de cada paraula, essent acompanyades per l'acostumat et cetera $^{89}$, que provocarà les disposicions reials del 1351 per tal de que els notaris redactin completament les notes i no abusin de les abreviatures.

\footnotetext{
${ }^{85} \mathrm{AHCR}$, Protocols notarials, R3-4, f. 20. Es tracta d'un dibuix realitzat amb puntets i que representa un porc.

${ }^{86}$ AHCR, Protocols notarials, R1, f. 17 v i f. 18 v.

${ }^{87} \mathrm{AHCR}$, Protocols notarials, R3-4, f. 40 v.

${ }^{88}$ Rafel GiNEBRA I MOLINS, Ibídem, p. 31.

${ }^{89} \mathrm{Cfr}$. José BONO HUERTA, 'Initia clausularum', "Rubrica. Trivium, Quadrivium, Studium", 4 (1990), pp. 75-96. També Josep M. PONS GURI, Característiques paleogràfiques, op. cit.', 1989 , pp. 206-218 presenta un corpus d'abreviatures $i$ frases que són molt útils per a la nostra recerca.
} 
Per acabar i pretenent fer un recull de tot el que hem dit veiem com la implantació del notariat públic a Reus és lenta i va penetrant poc a poc, almenys en la noció del notarius publicus. Un personatge, un càrrec que al llarg del segle XIII va lligat al món eclesiàstic, tal com ho havia estat tradicionalment a l'Alta Edat Mitjana en altres indrets. No obstant queda clar que el clergue que actua de notari ho fa perquè algú li dóna la fe pública. I la potestat per a fer-ho la té l'arquebisbe de Tarragona que concedeix la notaria al rector de la parròquia de Reus. Aquest delega en un notari.

Paral-lelament s'introdueixen l'instrument públic validat pel notari i posat en pública forma i la redacció de les notes en el manual o liber notularum. Les característiques d'aquests són similars i no difereixen més que en algunes variacions superficials dels que es conserven per a altres llocs.

En definitiva són qüestions que ens apropen al tema de la implantació del notariat públic a Reus des del punt de vista de la persona i de l'instrument. Caldrà en properes recerques analitzar l'altre punt important que és l'activitat notarial. De moment hem fet un primer pas per a descobrir un món prou desconegut per a la historiografia local.

\section{RÉSUMÉ}

Cet article analyse le fonctionnement du notariat à Reus au cours du XIII ${ }^{\mathfrak{e}}$ siècle, à partir de l'étude des souscriptions des notaires dans différents instruments validés par euxmêmes, dont certains déjà dès la moitié du XII ${ }^{e}$ siècle. Cette révision permet également d'observer l'évolution de l'implantation du notariat public, qui subit une transformation débutant en Italie a cette époque. Tout le mond voit, par ce travail, comment le notariat est lié au clergé pour des raisons jurisdictionnelles, et comment la charge de notaire est majoritairment occupée par les clercs de la paroisse, sous l'autorité du recteur. Enfin, l'auter décrit de façon sommaire les principales caractéristiques externes de la documentation produite par le notariat de Reus, représentée dans les manuels notariaux conservés dès la fin du XIII' siècle.

\section{SUMMARY}

This article analizes the functioning of the notarized in Reus along the XIII century. It is done from the subscription study of the notaries in different instruments accepted by them, some of them from the middle of XIIth century. This review allows to observe also the evolution in the implantation of the public notarized, that suffers a transformation started in 
Italy among these years. Everybody can see in this work how the notary is connected with the ecclesiastic statement because of jurisdictional reasons, and as the notary charge is occuped mainly by clergymen from the parrish, under the rector authority. Finally, the autor analyzes in a sumarial way the mainly external characteristics of the documentation produced in the notary from Reus, represented in the notarial handbooks that have been conserved from the en of the XIII century. 